\title{
Thermal Stress Analysis Considering Material Properties at Different Temperatures
}

\author{
Taekyung Kim ${ }^{1}$, Kwangju Lee ${ }^{2}$ \\ ${ }^{1}$ Department of Mechanical Engineering, Graduate School of KoreaTech \\ 1600 Chungjeol Ro, Byungcheon Myeon, Dongnam Gu, Cheonan City, Chungnam Province 31253, Republic of Korea \\ hgk7777@koreatech.ac.kr \\ ${ }^{2}$ School of Mechanical Engineering, KoreaTech \\ 1600 Chungjeol Ro, Byungcheon Myeon, Dongnam Gu, Cheonan City, Chungnam Province 31253, Republic of Korea \\ klee@koreatech.ac.kr
}

\begin{abstract}
The use of correct values of mechanical properties is important in the analysis of structures. The HVAC (heating, ventilation, air conditioning) unit of a passenger car had relatively wide temperature distribution and thus the correct values of material properties corresponding to its temperature must be used in its thermal stress analysis. In this paper, the mechanical properties of HVAC unit were found from experiments. Its temperature distribution was found assuming outdoor temperature to be $-10^{\circ} \mathrm{C}$ and heat core temperature to be $95^{\circ} \mathrm{C}$. Thermal stress of HVAC unit which resulted from its non-uniform temperature distribution was analysed. In the analysis the temperature dependent material properties were used. The results were compared with those using constant material properties which were found from experiments at room temperature.
\end{abstract}

Keywords: Mechanical properties of materials, HVAC unit, thermal stress, safety factor

\section{Introduction}

The effect of temperature on material properties has been studied by many researchers. Zhang et al. studied the influence of elevated temperature on the stability of sandwich structures [1]. They proposed a model to calculate the critical wrinkling stress, where the results were verified using four point bending tests. Pandey and Hemker performed uniaxial tension and stress relaxation tests to study the influence of crystallographic orientation on stress anisotropy and creep responses [2]. Chu et al. found that elastic modulus and strength tend to increase at cryogenic temperature because the binding forces between molecules are high at cryogenic temperature [3]. Mydin and Wang demonstrated that the loss in stiffness for foamed concrete at elevated temperatures occurs predominantly after about $90^{\circ} \mathrm{C}$, regardless of density as water expands and evaporates from the porous body [4]. Vosoughi et al. performed the thermal analysis of laminated composite beams [5]. They found that the temperature dependence of the material properties affects the thermal buckling and postbuckling characteristic of symmetrically laminated beams.

The mechanical properties of HVAC (heating, ventilation, and air conditioning) unit were measured at different temperature levels. Thermal stress was analysed using the experimentally measured material properties. They were compared with those using mechanical properties which were measured at room temperature.

\section{Mechanical Properties of HVAC Unit}

HVAC unit is made of polypropylene, mineral filler, and carbon nanotube. Their weight percentages are 64, 20, and $10 \%$, respectively. To find its mechanical properties, injection moulding was used to make specimens according to ASTM D 638 [6]. Type I specimen was used, which is preferred for sheet, plate, and moulded plastics. The specimens were tested using MTS 810 Material Testing System. To find material properties at different temperatures, MTS 651 Environmental Chamber was used. The temperature levels from $-20^{\circ} \mathrm{C}$ up to $100^{\circ} \mathrm{C}$ at an interval of $10^{\circ} \mathrm{C}$ were used in the tests. When the desired temperature was reached in the test chamber, the specimens were left inside the chamber for at least 20 minutes so that the temperature through the thickness of specimen could be uniform. 
The results of tests are plotted in Fig. 1 where stress-strain curves are shown. The stress-strain curves change significantly at lower temperatures. However the change was not significant at higher temperatures, which seem to be near or above glass transition temperature. The elastic modulus was found for strain up to $0.2 \%$ using linear regression model. The results were shown in Fig. 2. Elastic modulus and ultimate strength were summarized in Table 1.

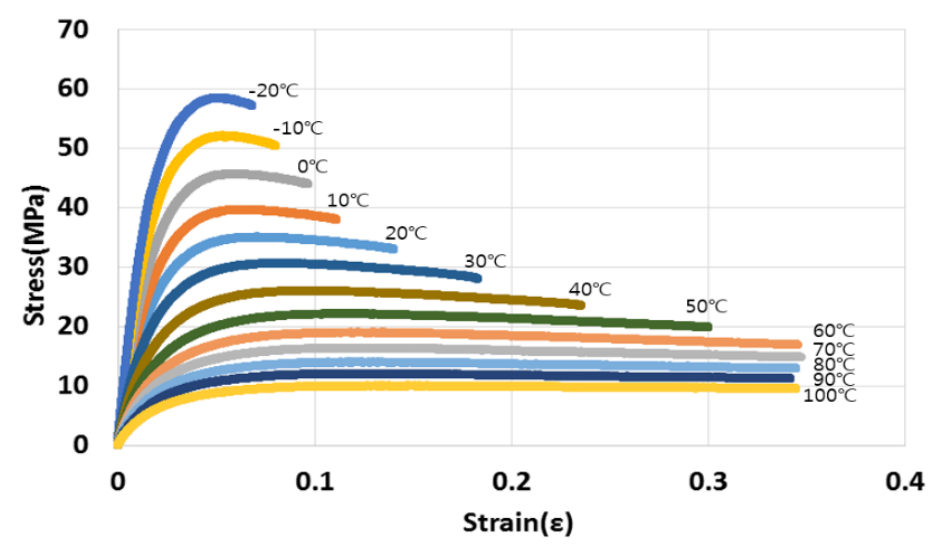

Fig. 1: Stress-strain curves at different temperatures.

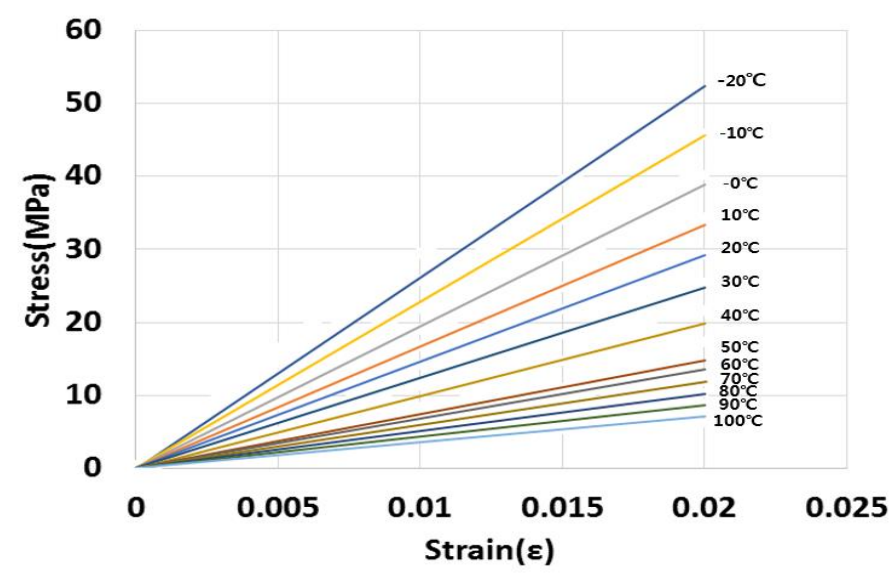

Fig. 2: Linear elastic behaviour of HVAC material which was found from linear regression models.

Table 1: Elastic modulus and ultimate strength at different temperature levels.

\begin{tabular}{|c|c|c|c|c|c|c|c|}
\hline Temperature $\left[{ }^{\circ} \mathrm{C}\right]$ & -20 & -10 & 0 & 10 & 20 & 30 & 40 \\
\hline Elastic Modulus [MPa] & 2,619 & 2,280 & 1,943 & 1,667 & 1,461 & 1,236 & 991 \\
\hline Ultimate Strength $[\mathrm{MPa}]$ & 58.6 & 52.2 & 45.8 & 39.7 & 35.1 & 30.7 & 26.1 \\
\hline
\end{tabular}

\begin{tabular}{|c|c|c|c|c|c|c|}
\hline Temperature $\left[{ }^{\circ} \mathrm{C}\right]$ & 50 & 60 & 70 & 80 & 90 & 100 \\
\hline Elastic Modulus [MPa] & 740 & 680 & 590 & 506 & 432 & 351 \\
\hline Ultimate Strength [MPa] & 21.1 & 19.05 & 16.4 & 14.1 & 12.1 & 10.1 \\
\hline
\end{tabular}




\section{Analysis of Temperature Distribution of HVAC Unit}

The temperature distribution of internal fluid flow inside HVAC unit was found using ANSYS Fluent. In the analysis, the temperature at the inlet was assumed to be $-10^{\circ} \mathrm{C}$ and the temperature of the heat core to be $95^{\circ} \mathrm{C}$. A CAD model of HVAC unit is shown in Fig. 3. The temperature distribution of internal flow is shown in Fig. 4.

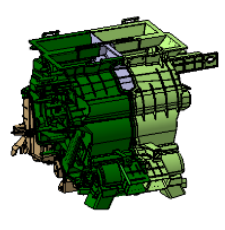

(a) assembled

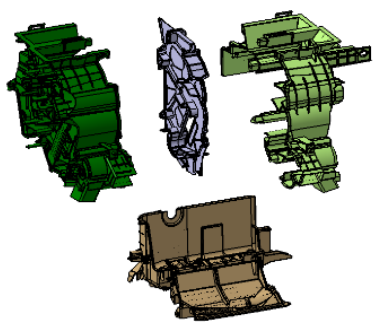

(b) unassembled

Fig. 3: CAD model of HVAC unit.
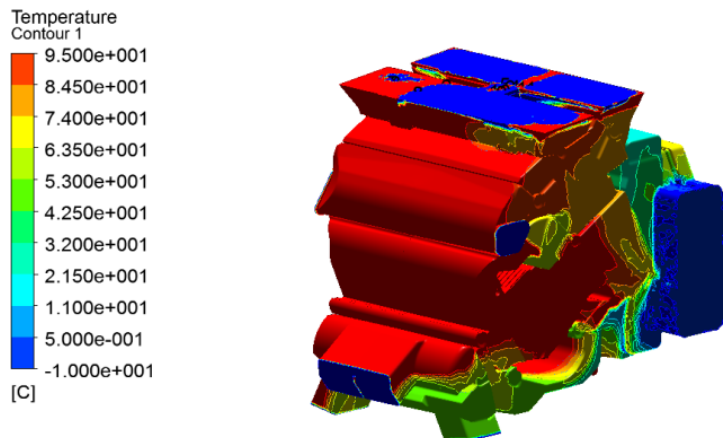

Fig. 4: Temperature distribution of internal flow inside HVAC unit.

The temperature distribution of HVAC unit was analysed using ANSYS Fluent. In the analysis, the convection boundary conditions were used with the results in Fig. 4 and outside temperature to be $-10^{\circ} \mathrm{C}$. The temperature distribution of HVAC unit was shown in Fig. 5.
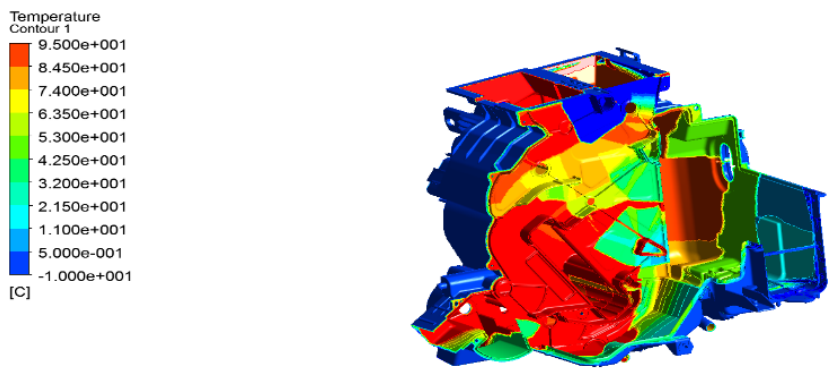

Fig. 5: Temperature distribution of HVAC unit.

\section{Thermal Stress Analysis of HVAC Unit}

The thermal stress distribution of HVAC unit was analysed using the results of temperature distribution in Fig. 5 and a commercial software ABAQUS. Elastic modulus which was found from tests at different levels of temperature was used in the analysis. Another analysis using elastic modulus from tests at $30^{\circ} \mathrm{C}$ was also performed. The results are summarized in Table 2. 
Table 2: Results of thermal stress analysis.

\begin{tabular}{|l|c|c|}
\hline \multirow{2}{*}{} & \multicolumn{2}{|c|}{ Elastic modulus which was used in the analysis } \\
\cline { 2 - 3 } & Temperature dependent & Found at $30^{\circ} \mathrm{C}$ \\
\hline Maximum stress $[\mathrm{MPa}]$ & 5.98 & 5.76 \\
\hline Temperature at max. stress $\left[{ }^{\circ} \mathrm{C}\right]$ & 62.15 & 73.24 \\
\hline Strength $[\mathrm{MPa}]$ & 18.75 & 15.75 \\
\hline Safety factor & 3.14 & 2.73 \\
\hline
\end{tabular}

The maximum stress which was found using elastic modulus from tests at different temperatures is $5.98 \mathrm{MPa}$ and is higher than 5.76 MPa which was found using elastic modulus from tests at 30oC. However, the safety factor was higher in the former considering the temperature and the strength where maximum stress occurs.

\section{Conclusions}

It is important to use correct values of material properties in the structural analysis. Proper values of material properties corresponding to the temperature must be used in the thermal stress analysis of HVAC unit of a passenger car. Otherwise the safety factor can be overestimated or underestimated. In the example problem, the safety factor was 3.14 when material properties were used from tests at different temperature levels. However, it was only 2.73 when material properties were used from tests at room temperature.

\section{Acknowledgements}

This research was partially supported by the Ministry of Trade, Industry, and Energy (MOTIE), Korea Institute for Advancement of Technology (KIAT) and Korea University of Technology and Education (Korea Tech.).

\section{References}

[1] S. Zhang, J. M. Dulieu-Barton, and O. T. Thomsen, "The effect of temperature on the failure modes of polymer foam cored sandwich structures," Composite Structures, vol. 121, pp. 104-113, 2015.

[2] A. Pandey and K. J. Hemker, "Temperature dependence of the anisotropy and creep in a single-crystal nickel superalloy," The Journal of the Minerals, Metals \& Materials Society, vol. 67, no. 7, pp.1617-1623, 2015.

[3] X.X. Chu, Z.X. Wu, R.J. Huang, L.F. Li, "Mechanical and thermal expansion properties of glass fibers reinforced PEEK composites at cryogenic temperatures," Cryogenics, vol. 50, no. 2, pp.84-88, 2010.

[4] M. A. O. Mydin and Y. C. Wang, "Mechanical properties of foamed concrete exposed to high temperature," Construction and Building Materials, vol. 26, no. 1, pp. 638-654, 2012.

[5] A. R. Vosoughi, P. Malekzadeh, Ma. R. Banan, and Mo. R. Banan, "Thermal buckling and postbuckling of laminated composite beams with temperature-dependent properties," International Journal of Non-Linear Mechanics, vol. 47, no. 3, pp. 96-102, 2012.

[6] ASTM International, "Standard Test Methods for Tensile Properties of Plastics," ASTM Designation D 638-02a, pp.46-58, 2002. 